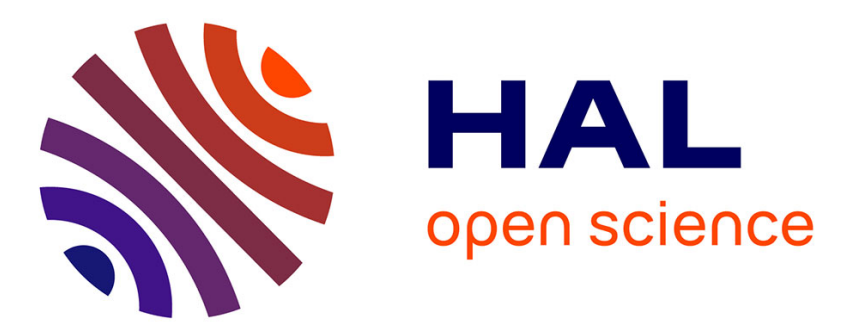

\title{
Anisotropic mechanical property variance between ASTM D638-14 type i and type iv fused filament fabricated specimens
}

\author{
John J Laureto, Joshua Pearce
}

\section{- To cite this version:}

John J Laureto, Joshua Pearce. Anisotropic mechanical property variance between ASTM D63814 type i and type iv fused filament fabricated specimens. Polymer Testing, 2018, 68, pp.294-301. 10.1016/j.polymertesting.2018.04.029 . hal-02111380

\author{
HAL Id: hal-02111380 \\ https://hal.science/hal-02111380
}

Submitted on 26 Apr 2019

HAL is a multi-disciplinary open access archive for the deposit and dissemination of scientific research documents, whether they are published or not. The documents may come from teaching and research institutions in France or abroad, or from public or private research centers.
L'archive ouverte pluridisciplinaire HAL, est destinée au dépôt et à la diffusion de documents scientifiques de niveau recherche, publiés ou non, émanant des établissements d'enseignement et de recherche français ou étrangers, des laboratoires publics ou privés. 
Preprint: John J. Laureto and Joshua M. Pearce. Anisotropic mechanical property variance between ASTM D638-14 type I and type IV fused filament fabricated specimens. Polymer Testing 68: 294-301 (2018). DOI: 10.1016/j.polymertesting.2018.04.029

\title{
Anisotropic Mechanical Property Variance Between ASTM D638-14 Type I and Type IV Fused Filament Fabricated Specimens
}

\author{
John J. Laureto ${ }^{1,2} \&$ Joshua M. Pearce ${ }^{1,3,4^{*}}$
}

1. Department of Materials Science \& Engineering, Michigan Technological University, Houghton MI.

2. United States Steel Corporation, Pittsburgh PA, USA

3. Department of Electronics and Nanoengineering, School of Electrical Engineering, Aalto University, Espoo, Finland.

4. Department of Electrical \& Computer Engineering, Michigan Technological University, Houghton, MI USA.

* Corresponding author: pearce@ mtu.edu

\begin{abstract}
The open source introduction of fused filament fabrication (FFF) enables distributed manufacturing of consumer products. However, with a wide range of low-cost FFF 3-D printers and settings possible, there is a lack of information on the variability in printed mechanical properties. This paper utilizes a large pool of 47 user-assembled 3-D printers to quantify the mechanical property variations of ultimate tensile strength (UTS) and yield strength of FFF printed components using ASTM D638-14 horizontally-oriented Type I and IV geometries for poly lactic acid (PLA). The results indicate that utilizing Type IV tensile test piece geometry may overestimate the UTS relative to the Type I. Furthermore, anisotropic mechanical property variances were quantified for Type IV specimens (vertical and horizontal orientations). Vertical tensile specimens had an ultimate tensile strength $47.9 \%$ less than horizontal. Finally, the abundant supply of PLA 3 -D prints suggest open-source printers assembled by individual operators can produce quality plastic components although the mechanical performance of the given part can vary dramatically based on the operator selection of printing parameters that provide a visually acceptable part.

\section{Highlights}

$>$ Wide range of FFF 3-D printers and settings create variability in printed mechanical properties

$>$ Here a large pool of user-assembled 3-D printers to quantify ultimate tensile strength (UTS)

$>$ and yield strength using ASTM D638-14 horizontally-oriented Type I and IV geometries

$>$ Tensile strengths of 61.6 and $60.9 \mathrm{MPa}$ were observed for Type IV and Type I, respectively

$>$ Check: Tensile component geometry is equivalent to the desired printed component geometry
\end{abstract}

Keywords: 3D Printing; mechanical testing; polylactic acid; RepRap; fused filament fabrication; FDM

\section{Introduction}

With the open source introduction of fused filament fabrication (FFF) with the self REPlicating RAPid Prototyper (RepRap) [1-3] technology, the low-cost 3-D printing market has expanded [4]. The advancement of FFF requires quantitative mechanical property characterization [5] based on process parameters [6]. Significant efforts have been made on this front including investigating impact absorption [7], frictional performance [8], strain rate sensitivity [9], fatigue [10] and tensile strength [11, 12]. In addition, past work has evaluated the effects of colorants [13], raster [14], raster and thickness [15-17], layer orientation [18], infill patterns [19], ambient gas [20], vibration of printer [21], porosity [22] and the number of cycles through the system for recycled polymers [23]. Furthermore, composites have been evaluated for the inclusion of waste bio materials [24], nanoparticles [25], wood fibre [26], waste wood [27], fibre reinformcent [28] and carbon nanotubes [29] on mechanical properties. Layer-wise manufacturing methods induce directionally dependent mechanical properties [12,30-33]. Anisotropy is most significant in a comparison between vertically and horizontally orientated, relative to the building platform, printed components. Optimized 
printing strategies need to be developed to alleviate the manufacturing effects. A recently published study utilizing powder based inkjet printing technology suggests that elimination of anisotropic effects requires a proper balance between layer thickness and part orientation [34]. Specifically, maximized mechanical properties can be achieved by ensuring critical component orientations are aligned coincident to the $\mathrm{X}$ axis build direction. Thus, deposited material (e.g. mechanical bonding agent) is layered in the largest available part dimension. Transposed to the FFF printing process, typically utilizing two dimensional layering coordinates (e.g. $\mathrm{X}$ and $\mathrm{Y}$ ), a larger printed cross-section yields optimized mechanical properties as the extruded material is deposited in relatively long vector passes. This is in agreement with references [12, 3033]. Similarly, one could view this as a reduction in the number of printed layers in the critical orientation increases the mechanical properties of the printed component.

In practice, optimizing a component's build orientation is not always possible due to the complexity of the part. Orienting a complex component to accommodate a specific design feature may have a negative influence on other areas of the component [35]. In addition, in this application, the manufacturing processes, build plate surface area and total build volume impose engineering design constraints on the operator. Consequently, assuming the critical metric is mechanical properties, components to be printed must be designed to be fabricated in the idealized build orientation to promote performance. Specifically, components are to be manufactured such that applied loads are induced axially along the deposition vector path [36]. These claims are complimented by [30, 35, 37]. While freedom of design is readily available to an engineer $[38,39]$ as layered manufacturing operations require no tooling, designing for manufacturing (e.g. understanding the limitations of a manufacturing process) is critical. Component design is complex, and thus compromises are required e.g. there is no perfect build orientation for every component to accommodate all design features. However, for a given component, the number of build orientations is finite. Cheng et al. suggests objective function software routines can be utilized to analyze component surfaces and features to determine optimum build orientations. The algorithms assign a weight factor to specific feature types (e.g. up facing horizontal flat surface that is easily printed or a leaning cylinder with no support that is more challenging to print as overhangs become larger) [40]. In practice, mechanical properties are not the only primary metric. Also to be considered are dimensional conformity to nominally-designed build files, speed of manufacture, surface quality and minimization of support volume [35, 36, 40, 41].

The notion that an optimized build geometry cannot always be achieved requires quantifying the mechanical properties in multiple build orientations. Also, not only build orientation, but other FFF printing parameters such as layer height $(\mathrm{mm})$, print temperature $\left({ }^{\circ} \mathrm{C}\right)$ and print speed $(\mathrm{mm} / \mathrm{s})$ will have a significant effect on resultant mechanical properties and must be considered. Previous work focuses on a single commercial 3-D printer unit. With the notable exception of [11] where random FFF printers and settings were analyzed for a wide range of RepRap 3-D printers, there is a dearth of information on the variability in mechanical properties of the largest class of desktop FFF 3-D printers (e.g. user-built RepRap variants). These printers are the lowest cost 3-D printers on the market, as observed on E-Bay, where costs have dropped to only several hundred dollars, enabling large-scale home-based distributed manufacturing of consumer products $[42,43]$. This paper aims to rectify the gaps of information available to design engineers focusing on product design for such a large pool of user-assembled 3-D printers by quantifying the mechanical property variation if FFF printed components using test methods described in ASTM D638 -14 [44]. Furthermore, this study will identify printing parameters to produce adequate mechanical properties by evaluating a range of printing parameters (e.g. print speed, nozzle temperature and layer height) within a range pre-determined by the operators to provide high-visual quality printed parts. Lastly, the study will evaluate the variability in evaluated mechanical property results (e.g. tensile and yield strength) of ASTM D638-14 Type I vs. Type IV geometries. The results will be analyzed and discussed to provide a material property database and guideline for the development of printing parameters. Moreover the applicability of Type I vs. Type IV test pieces will be reviewed in regards to time of manufacture and material consumption. Previous studies $[11,45]$ develop conclusions from Type I geometry at the expense of build time, material 
usage and the need for a large frame printer for sample development. The results presented in this document qualify the evaluated material property differences and provide insight into the necessity or lack thereof for both Type I vs. Type IV test pieces. In addition, anisotropic material property variances will be quantified with the tensile testing of Type IV specimens. Specifically, horizontally and vertically oriented components will be evaluated. Considerations to be discussed in this regard include cross sectional variation. Significant cross-sectional variances lead to incident build layer cooling rate variation. The effect of cooling rate variation on mechanical tensile properties (e.g. interlayer adhesion) will be evaluated.

\section{Methods}

The mechanical property variance of ASTM D638-14 Type I vs. Type IV tensile geometries was realized by fabrication of multiple test pieces with variable print parameters. The component files were generated in two forms to abide by the dimensional requirements listed in ASTM D638-14. Type I tensile components were downloaded from an online component database, while Type IV components were modeled using FreeCAD [46, 47]. Type IV components, to be printed vertically, were modeled with a sacrificial base to promote sufficient bed adhesion, while the other components were modeled per specification. Prior to mechanical testing, the sacrificial portion of the sample was removed. A vertically oriented print requires its largest linear dimension to be parallel to the Y-Z plane, while a horizontal build is parallel to the X-Y plane. Cura 15.04.6 was utilized for development of default print profiles whose parameters were contained in .ini files. Operators, constructing the test pieces, were instructed to vary 1) layer height (mm), 2) print speed $(\mathrm{mm} / \mathrm{s}), 3)$ print temperature $\left({ }^{\circ} \mathrm{C}\right)$, and 4$)$ flow $\%$ to generate a unique slice file. The remaining parameters were not available for modification and are displayed in Table 1. Thus, equivalent parameter sets were utilized for development of each printed .stl file with exception of the four primary metrics, as discussed previously. Furthermore, generated .stl files, as shown in Figure 1, were held in a constant position relative to the printing apparatus. Specifically, .amf files enabled the operator(s) to have reproducible part on build plate locations. Constant part location allows for equivalent layer time between all operators e.g. non-printing movements minimized dead time during cross-head travel resulting in non-uniform cooling of the test pieces. The selected part locations as per .stl grouping are identified in Figure 2. Test pieces of similar geometry (e.g. Type I and/or Type IV) were printed simultaneously given their build orientation. 


\begin{tabular}{|c|c|c|}
\hline Parameter Type & Metric & Value \\
\hline \multicolumn{3}{|l|}{ Quality } \\
\hline & Layer Height (mm) & Operator Set \\
\hline & $\begin{array}{l}\text { Shell Thickness } \\
(\mathrm{mm})\end{array}$ & 0.5 \\
\hline & Enable Retraction & Yes \\
\hline \multicolumn{3}{|c|}{ the } \\
\hline & Bottom/Top & 0.5 \\
\hline & Thickness (mm) & \\
\hline & Fill Density (\%) & 100 \\
\hline \multicolumn{3}{|l|}{ Temperature } \\
\hline & $\begin{array}{l}\text { Printing Temperature } \\
\left({ }^{\circ} \mathrm{C}\right)\end{array}$ & Operator Set \\
\hline \multicolumn{3}{|c|}{ (c) } \\
\hline & Diameter (mm) & 1.75 \\
\hline & Flow $(\%)$ & 100 \\
\hline \multicolumn{3}{|l|}{ Machine } \\
\hline & Nozzle Size (mm) & 0.5 \\
\hline \multicolumn{3}{|l|}{ Speed } \\
\hline & $\begin{array}{l}\text { Bottom Layer Speed } \\
(\mathrm{mm} / \mathrm{s})\end{array}$ & $\begin{array}{l}200 \\
15\end{array}$ \\
\hline & Infill Speed (mm/s) & $\begin{array}{l}\text { Operator Set via Print } \\
\text { Speed }\end{array}$ \\
\hline & $\begin{array}{l}\text { Top/Bottom Speed } \\
(\mathrm{mm} / \mathrm{s})\end{array}$ & $\begin{array}{l}\text { Operator Set via Print } \\
\text { Speed }\end{array}$ \\
\hline & $\begin{array}{l}\text { Outer Shell Speed } \\
(\mathrm{mm} / \mathrm{s})\end{array}$ & 60 \\
\hline & $\begin{array}{l}\text { Inner Shell Speed } \\
(\mathrm{mms})\end{array}$ & $\begin{array}{l}\text { Operator Set via Print } \\
\text { Speed }\end{array}$ \\
\hline \multicolumn{3}{|l|}{ In-Fill } \\
\hline & Solid Infill Top & Yes \\
\hline & Solid Infill Bottom & Yes \\
\hline & Infill Overlap (\%) & 15 \\
\hline & $\begin{array}{l}\text { Infill Prints after } \\
\text { Perimeters }\end{array}$ & Yes \\
\hline
\end{tabular}


Operators were instructed to print a total of nine tensile pieces using polylactic acid (PLA) - three for each type as opposed to five for ASTM standards. Individual operators selected their preferred PLA vendor (e.g. Hatchbox, Makerbot, Inland, 3D Solutech, Push Plastics, Digistruct, Excelvan, 3DP) [48-55]. However, acquired spools of raw filament had to have a nominal diameter of $1.75 \mathrm{~mm}$ (a machine requirement of the stock Athena Delta RepRap 3-D printer [56]). While considered a non-primary metric, any statistically significant variability in mechanical property data sets will be evaluated for raw material issues. Three of each test piece type were evaluated: ASTM D638-14 Type I (horizontal), Type IV (horizontal) and Type IV (vertical). Type I and Type IV horizontal specimens were manufactured in order to quantify variance in the sample dimensional types. Type IV specimen volume is $6,077 \mathrm{~mm}^{3}$, while Type I is $9,315 \mathrm{~mm}^{3}$ (e.g. $35 \%$ less volume). Ideally, engineering material properties (mechanical properties) can be adequately quantified with use of less filament material, so Type IV is the preferred methodology. In addition, interlayer adhesion of vertically oriented Type IV tensile bars is quantifiable. Similarly, the component total volume with sacrificial support material measures $7,205 \mathrm{~mm}^{3}$, which is still $22 \%$ less than Type I geometries with no support.

All test components were fabricated on an Athena variant of Michigan Tech's Open Sustainability's (MOST) Delta-style FFF 3-D printing [57]. Each printer was manufactured/assembled by a single operator following the build instructions developed by MOST [58]. Thus, clarity of assembly instructional operations along with operator performance will influence the reproducibility and repeatability of the Athena Delta's manufacturing processes. Specifically, poor printer framing (e.g. guide rods and supporting structure) would be expected to lead to difficulty during calibration procedures. Furthermore, while each Athena Delta is assembled with a similar Hexagon $1.75 \mathrm{~mm}$ hot end thermistor, calibration and installation will vary printer to printer. Thus, nominal temperatures readings may deviate from actual hot end temperature (e.g. providing variances to the parameter settings printer to printer). Figure 3 displays a representative build volume (250mm diameter, $240 \mathrm{~mm}$ high cylinder) and delta-style printer geometry.

In total, 423 total samples were expected from 47 operators generating 9 tensile samples ( 3 of each test piece type). Visual appearance (e.g. printing component quality) was utilized as an initial selection criterion. Test pieces with obvious missing print lines, porosity, and/or incomplete build processing were removed from the analysis selection pool. Gage length, width and thickness were verified prior to tensile testing and compared to ASTM D638-14 specification. Components failing the dimensional specification requirements in gage length section of the tensile bar were not utilized in the analysis. Finally, operator samples not abiding by project specifications (e.g. two printing temperatures in a single cycle) were removed from the analysis.

Mechanical testing operations were performed on an Instron 4206 with a $5.5 \mathrm{kN}$ load cell in accordance with ASTM D638-14's Section 5: Apparatus requirements. Test methods (e.g cross-head speed ( $\mathrm{mm} / \mathrm{min})$, strain rate $(\mathrm{mm} / \mathrm{mm}))$ and operational procedures for rigid and semi-rigid were set up following ASTM D63814's Section 8: Speed of Testing and Section 10: Procedure. Extensometer measurements were not collected due to multiple components fractures not occurring in the mid-span of the gage length. Similar to Tymrak et al., this phenomena is assumed to be due to stress concentrations formed by the tessellation on the exterior width of the rendered .stl file [11]. Resultant metrics; peak stress (MPa), strain at break (mm/mm), modulus (MPa) and yield stress (Mpa) were automatically calculated by the load frames control software MTS Test Works. Width and thickness $(\mathrm{mm})$ dimensional measurements were documented for every tensile specimens with electrical capacitance linear encode type calipers by a single operator. Optical inspection of all components was also performed prior to the measurement stage. A single operator was responsible for all mechanical testing processes to reduce the measurement variability along with similar tensile specimen preparation methods. 


\section{Results and Discussion}

The tensile strength property data collected from testing shows variability influenced by the printing parameters. The distribution of selected printing parameters by single operators are shown in Table 2. The relative distribution of printing parameters, shown in Table 2, indicates $0.2 \mathrm{~mm}$ layer height, $70 \mathrm{~mm} / \mathrm{s}$ printing speed, $210^{\circ} \mathrm{C}$ printing temperature and $100 \%$ flow are the most common operator parameters. The values described are similar to those discussed in the 'Printing Basics' section of the operator assembly guide [59]. This suggests that operators did not significantly deviate from known printing parameters with the exception of the user that utilized $200 \mathrm{~mm} / \mathrm{s}$ printing speed on nine printed test pieces.

In comparison of horizontally printed tensile test pieces, Type IV geometries outperformed Type I in maximum tensile strength (Mpa). Specifically, printing parameter conditions (e.g. layer height (mm), printer temperature $\left({ }^{\circ} \mathrm{C}\right)$, print speed $(\mathrm{mm} / \mathrm{s})$ and flow $(\%)$ yielded greater maximum tensile strength (MPa) for Type IV ranging from $4.4 \%$ to $17.0 \%$ greater than Type I. This is in agreement with the comparison of Type IV and I tests conducted by Torrado and Roberson, which looked a wide range of geometries and printing patterns for non-typical grade of acrylonitrile butadiene styrene (Cycola grade MG47) [60].

\begin{tabular}{|c|c|}
\hline Parameter Type & Specimens Considered \\
\hline \multicolumn{2}{|l|}{ Layer Height $(\mathrm{mm})$} \\
\hline 0.06 & 9 \\
\hline 0.09 & 9 \\
\hline 0.1 & 99 \\
\hline 0.15 & 90 \\
\hline 0.18 & 9 \\
\hline 0.2 & 135 \\
\hline 0.25 & 54 \\
\hline 0.3 & 9 \\
\hline 0.5 & 9 \\
\hline Total & 423 \\
\hline \multicolumn{2}{|l|}{ Print Temperature $\left({ }^{\circ} \mathrm{C}\right)$} \\
\hline 175 & 18 \\
\hline 180 & 27 \\
\hline 182 & 9 \\
\hline 185 & 45 \\
\hline 190 & 9 \\
\hline 200 & 45 \\
\hline 205 & 27 \\
\hline 210 & 171 \\
\hline 215 & 18 \\
\hline 220 & 9 \\
\hline 230 & 9 \\
\hline Total & 387 \\
\hline \multicolumn{2}{|l|}{ Print Speed $(\mathrm{mm} / \mathrm{s})$} \\
\hline 30 & 9 \\
\hline 40 & 18 \\
\hline 50 & 18 \\
\hline 55 & 9 \\
\hline 60 & 54 \\
\hline 67 & 9 \\
\hline 70 & 126 \\
\hline 75 & 9 \\
\hline 80 & 99 \\
\hline 85 & 18 \\
\hline 90 & 9 \\
\hline 200 & 9 \\
\hline Total & 387 \\
\hline \multicolumn{2}{|l|}{ Flow (\%) } \\
\hline 85 & 9 \\
\hline 90 & 9 \\
\hline 100 & 351 \\
\hline 104 & 9 \\
\hline 105 & 9 \\
\hline Total & 405 \\
\hline
\end{tabular}


Figures 4-7 indicate the distribution of parameters utilized and the corresponding maximum tensile strength (MPa) for Type I and Type IV tensile test pieces. Layer heights of $0.1 \mathrm{~mm}$ to $0.15 \mathrm{~mm}$ produce the largest Type IV test piece ultimate tensile strength (UTS) (MPa) measuring 61.2 $\mathrm{MPa}$ and 61.6 MPa, respectively. Similarly, Type I test pieces of the same parameter set, produced $60.9 \mathrm{MPa}$ and $57.2 \mathrm{MPa}$, respectively. Printing temperatures of $210^{\circ} \mathrm{C}$ corresponded with 0.1 and $0.15 \mathrm{~mm}$ layer heights. However, it should be noted that the $0.1 \mathrm{~mm}$ layer height operator utilized $103 \%$ flow while $0.15 \mathrm{~mm}$ layer height operator used the default value of $100 \%$.

To determine an optimized parameter set, collected data was isolated to only consider the most commonly utilized layer height (e.g. 0.1,0.15 and $0.2 \mathrm{~mm}$ ). Furthermore, operator parameter sets most often utilized a default $100 \%$ flow variable. Thus, all parameter set values greater and/or less than $100 \%$ were excluded from the data set. In this method, holding layer height and flow percentage constant allows for the comparison. Contour plots generated in Figures $8-10$ show the parameters required to obtain the maximum ultimate tensile strength of a PLA ASTM D638-14 Type I and/or Type IV tensile test pieces.

The described contour plots allow for a correlation of speed $(\mathrm{mm} / \mathrm{s})$ and print temperature $\left({ }^{\circ} \mathrm{C}\right)$ to derive a printing parameter set to best promote a relatively high UTS. Layer heights of 0.1 to $0.15 \mathrm{~mm}$ are most readily suitable to produce a PLA UTS greater than $60 \mathrm{Mpa}$. Specifically, at both layer heights, a print temperature of $210\left({ }^{\circ} \mathrm{C}\right)$ produced the largest UTS for both Type I and Type IV tensile test pieces. The analysis does not suggest printing speed has much influence on UTS within a given layer height of 0.1 or $0.2 \mathrm{~mm}$. However, there does appear to be a correlation with layer heights of $0.15 \mathrm{~mm}$, where a constant print temperature is considered, UTS decreases with increased printing speed. Figure 10 shows an anomaly in the data set where printing temperatures $200-210{ }^{\circ} \mathrm{C}$ at $\sim 70 \mathrm{~mm} / \mathrm{s}$ yield low tensile strength values relative to the dataset population. The region in question is the result of poor sample development from an operator. Specifically, the data in this regions deviates (-) $2 \sigma$ from the $0.2 \mathrm{~mm}$ layer height UTS mean. On average, the observed tensile properties for Type I and Type IV test pieces are equivalent to other resources available in the literature $[6,11,31,45]$.

Variable print orientation influence on the anisotropic performance of an FFF (or FDM) printed components' UTS for Type IV tensile test pieces is also considered. The results of this study are in accordance with a study of single layer $90^{\circ}$ vs. single layer $0^{\circ}$ samples (e.g. tensile loading direction is perpendicular and/or parallel to printer raster lines), as presented by Casavola et al [31]. They compared single layer $90^{\circ}$ specimens to $0^{\circ}$ specimens and reported 55.2\% lower UTS compared to the $90^{\circ}$ counterpart [31]. During printing, operators struggled to maintain dimensional conformity and part quality as printed in the vertical orientation. Small cross-sectional area of a given layer proved difficult to control in the provided parameter settings. Components failing inspection criteria, as described above, were eliminated from the analysis. On average, vertically oriented Type IV tensile specimens have a UTS $47.9 \%$ less than their horizontally printed equivalent (e.g. utilizing the same printing parameters and where the only variable is component orientation). A comparison is made of Type I vs. Type IV UTS data over a range of parameters including layer height $(\mathrm{mm})$, print temperature $\left({ }^{\circ} \mathrm{C}\right)$, print speed $(\mathrm{mm} / \mathrm{s})$ and flow \% for vertical and horizontal UTS values in Figure $11-14$.

Due in part to the results of this study it is clear that desktop 3-D printing has clearly come a long way from when it was used primarily for making visual prototypes. With the mechanical testing completed in the literature and further refined in this study, the opportunity is presented to use FFF printers for fabrication of mechanical load-bearing parts for a wide range of applications for both home consumers as well as most industry. Perhaps most intriguing is the ability of open source DIY built RepRap printers to assist in sustainable development [61,62]. With both individuals and communities now able to print products with 
mechanical strength to meet their applications in the developing countries [63,64], even including farming tools [65], a new large potential for economic development is made available.

Realized parameter values are specific to the cross-sectional geometry printed. The temperature distribution within the part is dependent on the motion of the localized heating cross-head and cross-sectional component size [66]. Thus, the variable temperature profile distribution will affect the interlayer bonding characteristics and subsequent mechanical properties. Cautionary measures should then be taken during parameter optimization for geometries not similar to ASTM D638-14 Type I and Type IV tensile bars.

Vertical test specimens had on average about half the tensile strength of the horizontal specimens, which underlines the need to think carefully about the print orientation for part strength. It should also be pointed out that, in general, the tensile strength of FFF parts is not as high as bulk properties. For example, pure PLA has been shown to have a tensile strength of about $66 \mathrm{MPa}$ with no printing in the bulk form [67]. Whenever possible, printing should be done where the forces are in parallel with the print direction/orientation. When this is not possible, in the short term this can be overcome by having a two part print, with one part providing mechanical strength while the other part provides aesthetic or other functions. So, for example, a hammer handle may need to be printed with a custom ergonomic grip with the length of the hammer leading away from the print bed. Conventionally printing the handle in one piece would create a potential line of failure in between each layer when force is applied to the hammer shaft along the 3-D printed layer lines. If the ergonomic aspects are printed only on the surface of the hammer handle and the center of the shaft is printed hollow, a second component can be printed with the print layers running the length of the shaft. When the two components are combined, the mechanical strength of the horizontal values can be expected. Similarly, the mechanical strength can be fortified with metal components (e.g. a threaded rod and bolt used in the interior of 3-D printed solar photovoltaic racking brackets [68]). In the medium term, with improvised slicing software and higher degrees of mechanical freedom, it may be possible to print most geometries in true voxel format so that the slice lines for printing can be oriented optimally despite the part orientation. Similarly, it may be possible to map an already printed object to print on top of it. So for example, the optimally oriented print of the inner shaft of a hammer could then have an ergonomic grip printed on top of it directly. This would eliminate the need for the combined approach, which requires assembly.

\section{Conclusions}

The mechanical properties of ASTM D638-14 Type I and Type IV tensile bar specimens were characterized. Multiple parameter types were evaluated utilizing 47 printers and operators fabricating 423 tensile bars. Horizontally oriented Type I and Type IV specimens are evaluated to quantify the variance between the two geometry types. At a maximum, tensile strengths of 61.6 and $60.9 \mathrm{MPa}$ were observed for Type IV and Type I, respectively. Furthermore, anisotropic mechanical property variances were quantified for Type IV specimens using vertically oriented and horizontally printed specimens. Vertical tensile specimens had an ultimate tensile strength $47.9 \%$ lower than their horizontal counterparts. The results tabulated indicate that utilizing Type IV tensile test piece geometries may overestimate the UTS relative to the Type I. Thus, considerations must be made to insure a tensile component geometry is equivalent to the desired printed component geometry. Moreover, the abundant supply of printing tensile specimens and subsequent printed PLA components suggest that open-source printers assembled by individual operators can produce quality plastic components suitable for engineering applications.

\section{Acknowledgements}

The authors would like to thank the Fall 2016 students of Michigan Technological University's MY4777/MY5777 and EE4777/EE5777 for supply of the ASTM B638-14 mechanical testing specimens. This project was supported by the Michigan Tech Open Sustainability Technology Laboratory and Fulbright Finland. 


\section{References}

[1] Jones, Rhys, Patrick Haufe, Edward Sells, Pejman Iravani, Vik Olliver, Chris Palmer, and Adrian Bowyer. "RepRap-the replicating rapid prototyper." Robotica 2011, 29, no. 01: 177-191.

[2] Sells, E., Smith, Z., Bailard, S., Bowyer, A. \& Olliver, V. in Piller, F. T.; Tseng, M. M. Handbook of Research in Mass Customization and Personalization: (In 2 Volumes) 2009, World Scientific Publishing Company.

[3] Bowyer, A. 3D Printing and Humanity's First Imperfect Replicator. 3D printing \& Additive Manufacturing 2014, 1.1, 4-5.

[4] Wohlers, T., 2016. Wohlers report 2016. Wohlers Associates, Inc.

[5] Tanikella, N.G., Wittbrodt, B. and Pearce, J.M., Tensile Strength of Commercial Polymer Materials for Fused Filament Fabrication 3-D Printing. Additive Manufacturing 2017, 15, 40-47. DOI: 10.1016/j.addma.2017.03.005

[6] Lanzotti, A., Grasso, M., Staiano, G. and Martorelli, M. The impact of process parameters on mechanical properties of parts fabricated in PLA with an open-source 3-D printer. Rapid Prototyping Journal 2015, 21(5), pp.604-617.

[7] Tsouknidas, A., Pantazopoulos, M., Katsoulis, I., Fasnakis, D., Maropoulos, S. and Michailidis, N. Impact absorption capacity of 3D-printed components fabricated by fused deposition modelling. Materials \& Design 2016, 102, pp.41-44.

[8] Leacock AG, Cowan G, Cosby M, Volk G, McCracken D, Brown D. Structural and Frictional Performance of Fused Deposition Modelled Acrylonitrile Butadiene Styrene (P430) with a view to use as Rapid Tooling Material in Sheet Metal Forming. Key Engineering Materials, 2014.,639.

[9] Vairis A, Petousis M, Vidakis N, Savvakis K. On the Strain Rate Sensitivity of Abs and Abs Plus Fused Deposition Modeling Parts. Journal of Materials Engineering and Performance 2016, 25(9):3558-65.

[10]Afrose MF, Masood SH, Iovenitti P, Nikzad M, Sbarski I. Effects of part build orientations on fatigue behaviour of FDM-processed PLA material. Progress in Additive Manufacturing 2016, (1-2):21-8.

[11]Tymrak, B. M.; Kreiger, M.; Pearce, J. M. Mechanical properties of components fabricated with opensource 3-D printers under realistic environmental conditions. Materials \& Design 2014, 58, 242-246 DOI: 10.1016/j.matdes.2014.02.038.

[12]F. Johansson. "Optimizing Fused Filament Fabrication 3D printing for durability: Tensile properties and layer bonding”, M.S. thesis, Dept. Mechanical Eng., Blekinge Institue of Technology, Karlskrona, Sweden, 2016.

[13]Wittbrodt, B.; Pearce, J. M. The effects of PLA color on material properties of 3-D printed components. Additive Manufacturing 2015, 8, 110-116 DOI: 10.1016/j.addma.2015.09.006.

[14]Cantrell, J., Rohde, S., Damiani, D., Gurnani, R., DiSandro, L., Anton, J., Young, A., Jerez, A., Steinbach, D., Kroese, C. and Ifju, P. Experimental Characterization of the Mechanical Properties of 3D Printed ABS and Polycarbonate Parts. In Advancement of Optical Methods in Experimental Mechanics, Volume 3 2017, (pp. 89-105).

[15]Wu W, Geng P, Li G, Zhao D, Zhang H, Zhao J. Influence of layer thickness and raster angle on the mechanical properties of 3D-printed PEEK and a comparative mechanical study between PEEK and ABS. Materials. 2015, 8(9):5834-46.

[16]Rankouhi, B., Javadpour, S., Delfanian, F. and Letcher, T. Failure analysis and mechanical characterization of 3D printed ABS with respect to layer thickness and orientation. Journal of Failure Analysis and Prevention 2016, 16(3), pp.467-481.

[17]Fernandez-Vicente M, Canyada M, Conejero A. Identifying limitations for design for manufacturing with desktop FFF 3D printers. International Journal of Rapid Manufacturing 2015, 5(1):116-28.

[18]Es-Said, O. S.; Foyos, J.; Noorani, R.; Mendelson, M.; Marloth, R.; Pregger, B. A. Effect of Layer Orientation on Mechanical Properties of Rapid Prototyped Samples. Materials and Manufacturing Processes 2000, 15 (1), 107-122 DOI: 10.1080/10426910008912976 
[19]Fernandez-Vicente, M., Calle, W., Ferrandiz, S. and Conejero, A., Effect of Infill Parameters on Tensile Mechanical Behavior in Desktop 3D Printing. $3 D$ Printing and Additive Manufacturing 2016, 3(3), pp.183-192.

[20]Lederle, F., Meyer, F., Brunotte, G.P., Kaldun, C. and Hübner, E.G., Improved mechanical properties of 3D-printed parts by fused deposition modeling processed under the exclusion of oxygen. Progress in Additive Manufacturing 2016, 1(1-2), pp.3-7.

[21]Pilch Z, Domin J, Szłapa A. The impact of vibration of the 3D printer table on the quality of print. In Selected Problems of Electrical Engineering and Electronics (WZEE) 2015, (pp. 1-

[22]Chin Ang, K.; Fai Leong, K.; Kai Chua, C.; Chandrasekaran, M. Investigation of the mechanical properties and porosity relationships in fused deposition modelling-fabricated porous structures. Rapid Prototyping Journal 2006, 12 (2), 100-105 DOI: 10.1108/13552540610652447.

[23]Cruz, Fabio, Silvia Lanza, Hakim Boudaoud, Sandrine Hoppe, and Mauricio Camargo. Polymer Recycling and Additive Manufacturing in an Open Source context: Optimization of processes and methods. In 2015 Annual International Solid Freeform Fabrication Symposium-An Additive Manufacturing Conference 2015, Austin, Texas (USA), pp. 10-12.

[24]Girdis J, Gaudion L, Proust G, Löschke S, Dong A. Rethinking Timber: Investigation into the Use of Waste Macadamia Nut Shells for Additive Manufacturing. JOM 2016, 1-5.

[25]Meng S, He H, Jia Y, Yu P, Huang B, Chen J. Effect of nanoparticles on the mechanical properties of acrylonitrile-butadiene-styrene specimens fabricated by fused deposition modeling. Journal of Applied Polymer Science 2017, 134(7).

[26]Le Duigou, A., Castro, M., Bevan, R. and Martin, N., 3D printing of wood fibre biocomposites: from mechanical to actuation functionality. Materials \& Design 2016, 96, pp.106-114.

[27]Pringle, A. M., Rudnicki, M., Pearce, J. Wood Furniture Waste-Based Recycled 3-D Printing Filament. Forest Products Journal 2017, https://doi.org/10.13073/FPJ-D-17-00042

[28]Türk DA, Brenni F, Zogg M, Meboldt M. Mechanical characterization of 3D printed polymers for fiber reinforced polymers processing. Materials \& Design. 2017 Mar 15;118:256-65.

[29]Gardner JM, Sauti G, Kim JW, Cano RJ, Wincheski RA, Stelter CJ, Grimsley BW, Working DC, Siochi EJ. 3-D printing of multifunctional carbon nanotube yarn reinforced components. Additive Manufacturing. 2016 Oct 31;12:38-44.

[30]Ahn, S.; Montero, M.; Odell, D.; Roundy, S.; Wright, P. K. Anisotropic material properties of fused deposition modeling ABS. Rapid Prototyping Journal 2002, 8 (4), 248-257 DOI: $10.1108 / 13552540210441166$.

[31]Casavola, C., Cazzato, A., Moramarco, V. and Pappalettere, C. Orthotropic mechanical properties of fused deposition modelling parts described by classical laminate theory. Materials \& Design 2016, 90, pp.453-458.

[32]Zou R, Xia Y, Liu S, Hu P, Hou W, Hu Q, Shan C. Isotropic and anisotropic elasticity and yielding of 3D printed material. Composites Part B: Engineering. 2016 Aug 15;99:506-13.

[33]Rybachuk, M., Alice Mauger, C., Fiedler, T., Öchsner, A. Anisotropic mechanical properties of fused deposition modeled parts fabricated by using acrylonitrile butadiene styrene polymer. Journal of Polymer Engineering 2017, DOI:10.1515/polyeng-2016-0263

[34]Farzadi, Arghavan, Mehran Solati-Hashjin, Mitra Asadi-Eydivand, and Noor Azuan Abu Osman. "Effect of layer thickness and printing orientation on mechanical properties and dimensional accuracy of 3D printed porous samples for bone tissue engineering." PloS one 9, no. 9 (2014): e108252.

[35]Taufik, Mohammad, and Prashant K. Jain. Role of build orientation in layered manufacturing: a review. International Journal of Manufacturing Technology and Management 2013 27, no. 1-3: 47-73.

[36]Durgun, Ismail, and Rukiye Ertan. "Experimental investigation of FDM process for improvement of mechanical properties and production cost." Rapid Prototyping Journal 2014, 20, no. 3: 228-235.

[37]Sood, Anoop Kumar, Raj K. Ohdar, and Siba S. Mahapatra. "Parametric appraisal of mechanical property of fused deposition modelling processed parts." Materials \& Design 201031, no. 1 (): 287-295. 
[38]Petrick, Irene J., and Timothy W. Simpson. "3D printing disrupts manufacturing: how economies of one create new rules of competition." Research-Technology Management 56, no. 6 (2013): 12-16.

[39]Hague, Richard, Saeed Mansour, and Naguib Saleh. "Material and design considerations for rapid manufacturing." International Journal of Production Research 42, no. 22 (2004): 4691-4708.

[40]Cheng, W., J. Y. H. Fuh, A. Y. C. Nee, Y. S. Wong, H. T. Loh, and T. Miyazawa. "Multi-objective optimization of part-building orientation in stereolithography." Rapid Prototyping Journal 19951, no. 4: 12-23.

[41]Ezair, Ben, Fady Massarwi, and Gershon Elber. "Orientation analysis of 3D objects toward minimal support volume in 3D-printing." Computers \& Graphics 2015,51): 117-124.

[42]Wittbrodt BT, Glover AG, Laureto J, Anzalone GC, Oppliger D, Irwin JL, Pearce JM. Life-cycle economic analysis of distributed manufacturing with open-source 3-D printers. Mechatronics. 2013 Sep 30;23(6):713-26.

[43]Petersen EE, Pearce J. Emergence of Home Manufacturing in the Developed World: Return on Investment for Open-Source 3-D Printers. Technologies. 2017 Feb 9;5(1):7.

[44]Standard Test Method for Tensile Properties of Plastics, ASTM Standard D628-02a

[45]Wittbrodt, Ben, and Joshua M. Pearce. "The effects of PLA color on material properties of 3-D printed components." Additive Manufacturing 2015 pg. 110-116.

[46] Thingiverse [Online]. Available: (http://www.thingiverse.com/)

[47] FreeCAD [Online]. Available: (https://www.freecadweb.org/)

[48] Hatchbox Filament [Online]. Available: (http://hatchbox3d.com/)

[49] Makerbot Filament [Online]. Available: (https://store.makerbot.com/filament/)

[50] Inland Plastics [supplier website unavailable]

[51] 3D Solutech [Online\}. Available: (http://www.3dsolutech.com/)

[52] Push Plastics [Online]. Available: (https://www.pushplastic.com/)

[53] Digistruct [supplier website unavailable]

[54] Excelvan [supplier website unavailable]

[55]3DP [Online]. Available: (https://3dpfilament.ink/)

[56]Anzalone, G., Wijnen, B., Pearce, J.M., Multi-material additive and subtractive prosumer digital fabrication with a free and open-source convertible delta RepRap 3-D printer, Rapid Prototyping Journal 2015, 21(5), pp.506 - 519 DOI:http://dx.doi.org/10.1108/RPJ-09-2014-0113

[57]MOST Delta [Online]. Available: (http://www.appropedia.org/Delta_Build_Overview:MOST)

[58]Athena Build Guide [Online]. Available: (http://www.appropedia.org/Athena_Build_Overview)

[59]MY5777/EE5777 Class Page [Online]. Available: http://www.appropedia.org/Athena_Printing_Basics

[60] Torrado A,R., Roberson, D, A. Failure Analysis and Anisotropy Evaluation of 3D-Printed Tensile Test Specimens of Different Geometries and Print Raster Patterns. J Fail Anal and Preven. 2016;16(1):15464. DOI: 10.1007/s11668-016-0067-4

[61]Pearce, J.M., Blair, C.M., Laciak, K.J., Andrews, R., Nosrat, A. and Zelenika-Zovko, I., 3-D printing of open source appropriate technologies for self-directed sustainable development. Journal of Sustainable Development 2010, 3(4), 17-29. DOI: http://dx.doi.org/10.5539/jsd.v3n4p17

[62]Birtchnell, T. and Hoyle, W. 3D printing for development in the global south: The 3D4D challenge. Springer 2014.

[63]Campbell, T., Williams, C., Ivanova, O. and Garrett, B. Could 3D printing change the world. Technologies, Potential, and Implications of Additive Manufacturing, Atlantic Council 2014, Washington, DC.

[64]Canessa, E., Fonda, C., Zennaro, M. Low-cost 3D printing for science, education and sustainable development. Low-Cost 3D Printing 2013.

[65]Pearce, J.M., Applications of open source 3-D printing on small farms. Organic Farming 2015, 1(1), pp.19-35. DOI: 10.12924/of2015.01010019 
[66]Sun, Q.; Rizvi, G. M.; Bellehumeur, C. T.; Gu, P. Effect of processing conditions on the bonding quality of FDM polymer filaments. Rapid Prototyping Journal 2008, 14 (2), 72-80 DOI: $10.1108 / 13552540810862028$.

[67]Baiardo, M., Frisoni, G., Scandola, M., Rimelen, M., Lips, D., Ruffieux, K., \& Wintermantel, E. Thermal and mechanical properties of plasticized poly (L-lactic acid). Journal of Applied Polymer 2003, 90(7), 1731-1738.

[68]Wittbrodt, B.T., Pearce, J.M., Total U.S. cost evaluation of low-weight tension-based photovoltaic flatroof mounted racking. Solar Energy 2015, 117, 89-98 DOI: 10.1016/j.solener.2015.04.026 


\section{Figure Captions}

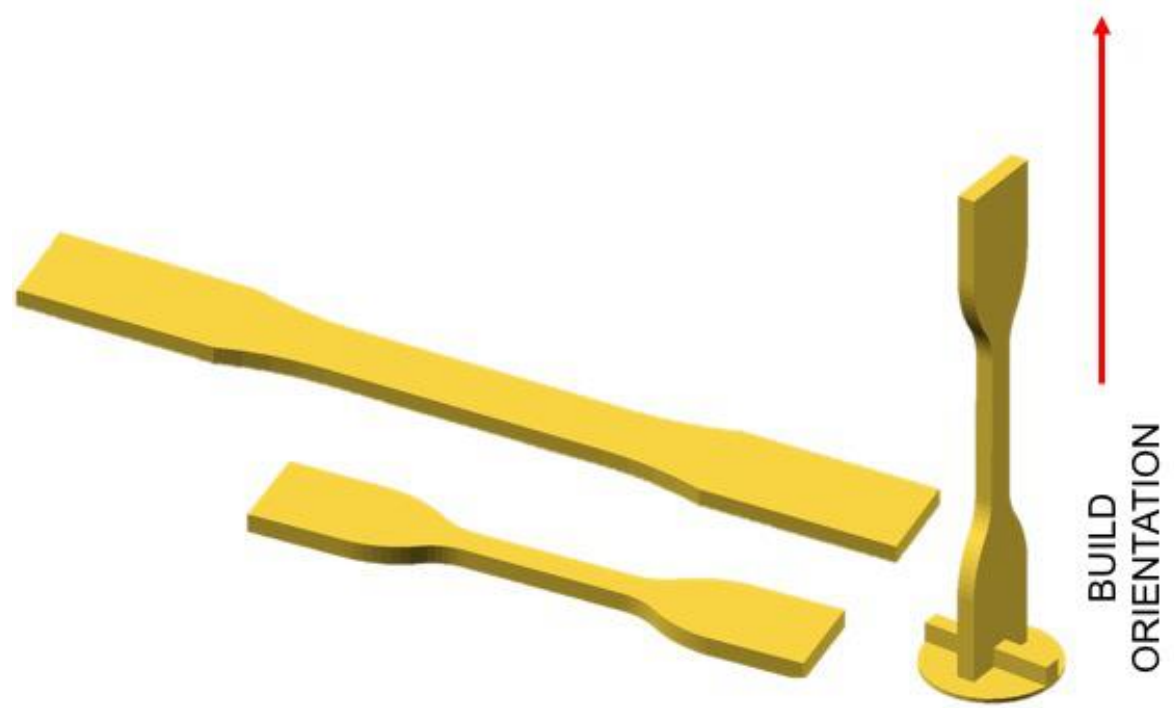

Fig. 1. Generated .stl files for the variants of ASTM D638-14 Type I vs. Type IV tensile bars.
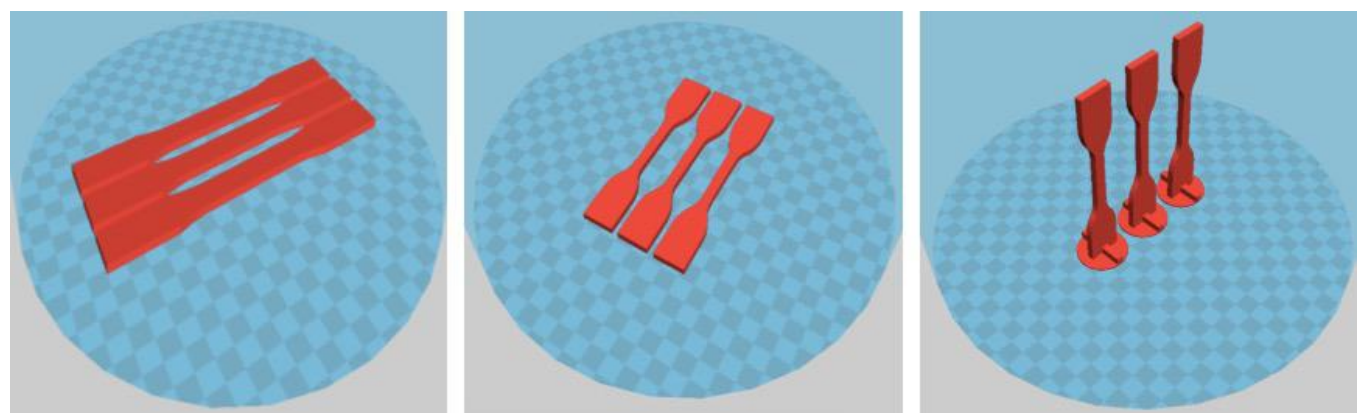

Fig. 2. Cura 15.04.06 Athena Delta printer build volume and part layout representation of generated .amf files. Variants of ASTM D638-14 Type I (left) vs. Type IV flat (middle) and Type IV vertical (right) tensile bar.

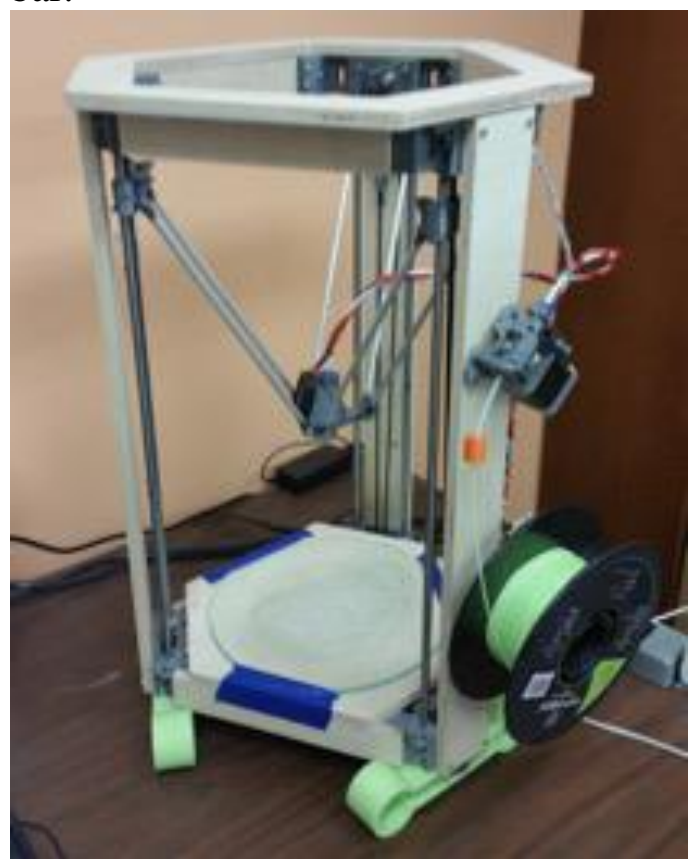

Fig. 3. Build volume and open-source RepRap Athena 3-D Printer. 


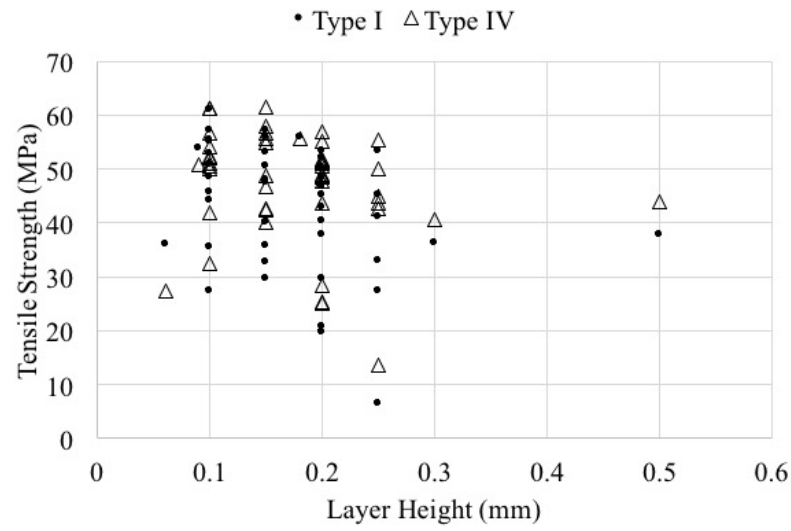

Fig. 4. Tensile strength (MPa) distribution. ASTM D638-14 Type I geometries are compared against Type IV at equivalent printing parameters: Layer Height $(\mathrm{mm})$.

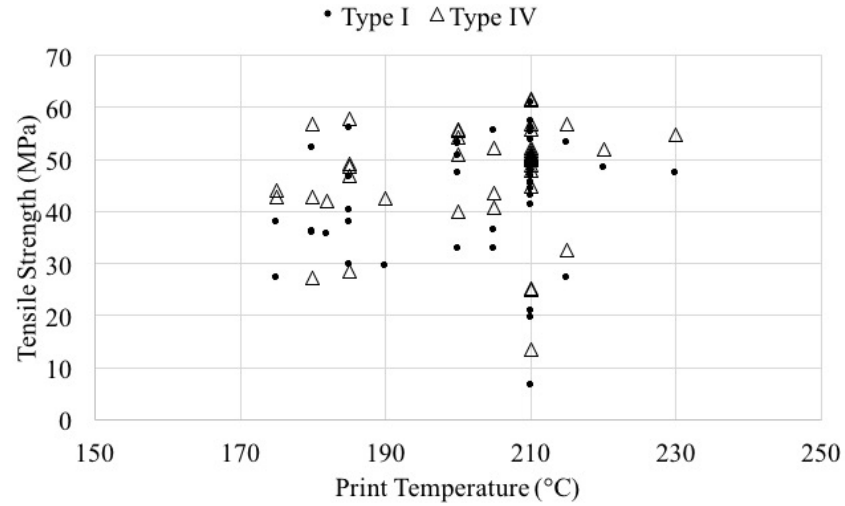

Fig. 5. Tensile strength (MPa) distribution. ASTM D638-14 Type I geometries are compared against Type IV at equivalent printing parameters: Print Temperature $\left({ }^{\circ} \mathrm{C}\right)$.

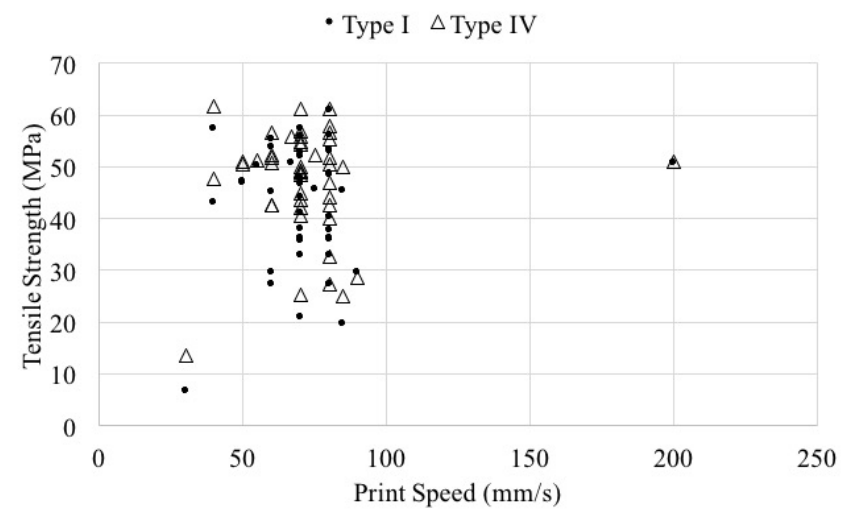

Fig. 6. Tensile strength (MPa) distribution. ASTM D638-14 Type I geometries are compared against Type IV at equivalent printing parameters: Printing Speed $(\mathrm{mm} / \mathrm{s})$. 
- Type I $\Delta$ Type IV

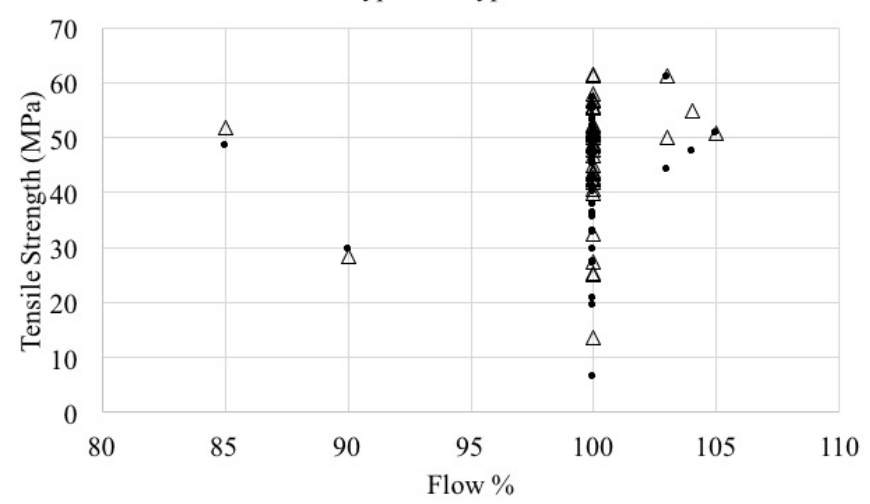

Fig. 7. Tensile strength (MPa) distribution. ASTM D638-14 Type I geometries are compared against Type IV at equivalent printing parameters: Flow (\%).
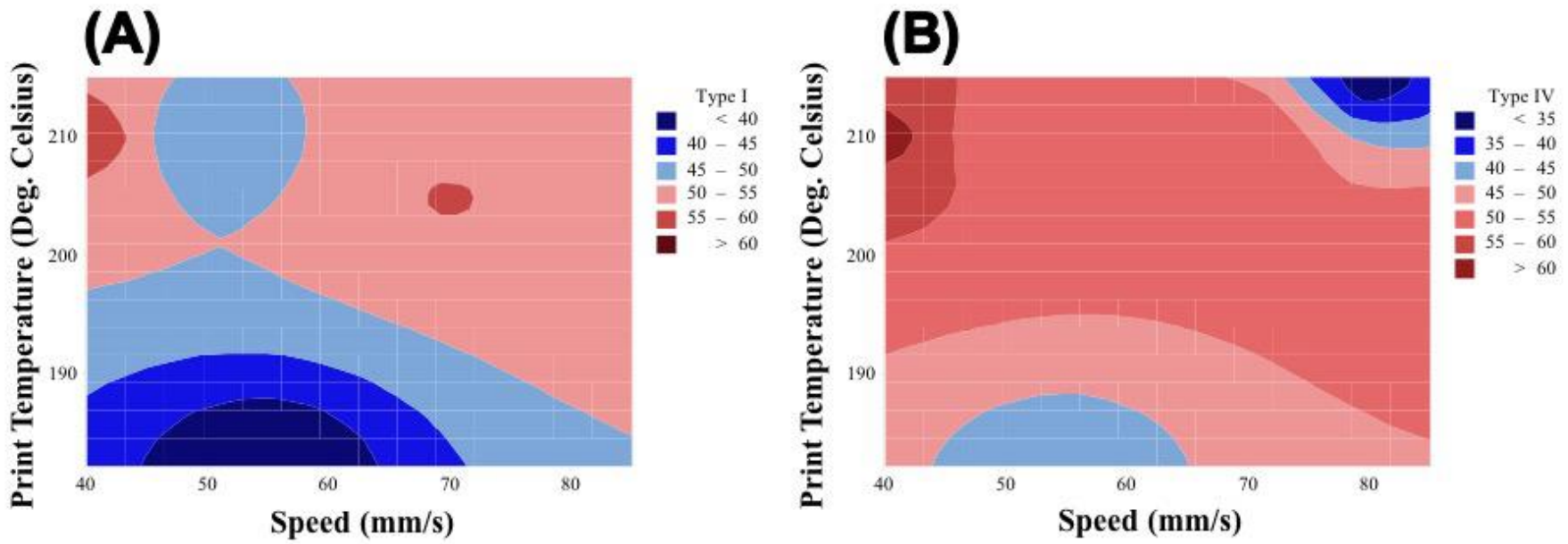

Fig. 8. Contour plot describing maximum UTS (MPa) at a layer height of $0.1 \mathrm{~mm}$. Variable parameters are print speed $(\mathrm{mm} / \mathrm{s})$ and print temperature $\left({ }^{\circ} \mathrm{C}\right)$. (a) Type I, (b) Type IV.

(A)

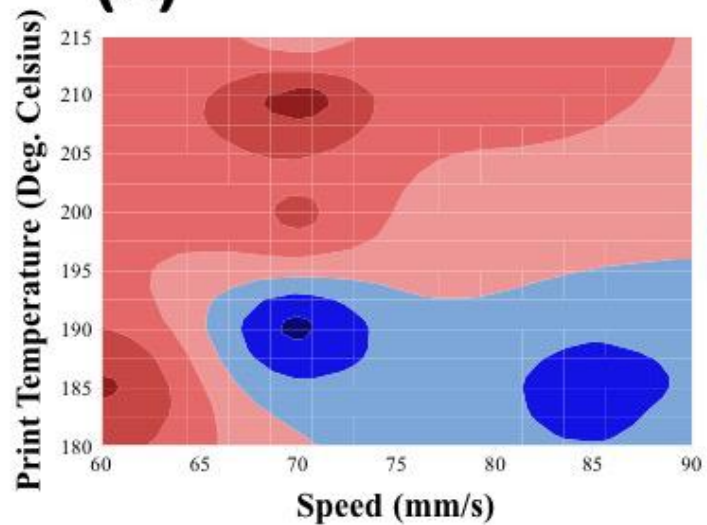

(B)

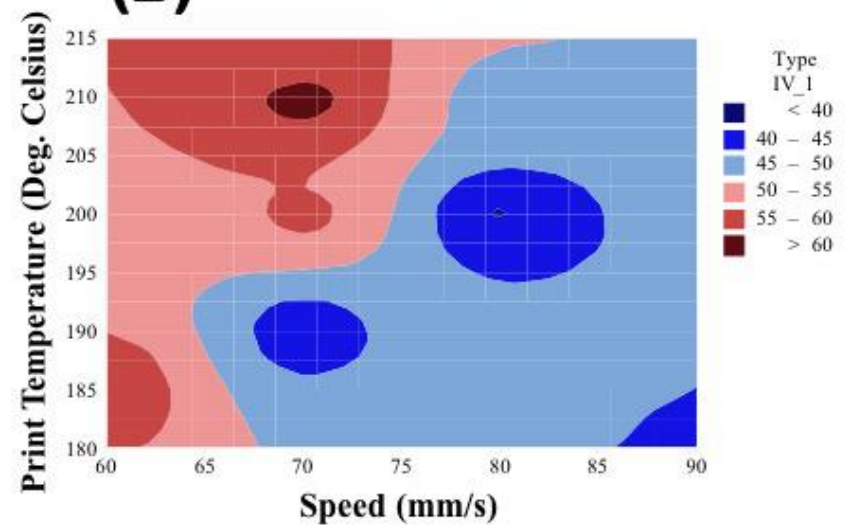

Fig. 9. Contour plot describing maximum UTS (MPa) at a layer height of $0.15 \mathrm{~mm}$. Variable parameters are print speed $(\mathrm{mm} / \mathrm{s})$ and print temperature $\left({ }^{\circ} \mathrm{C}\right)$. (a) Type I, (b) Type IV. 

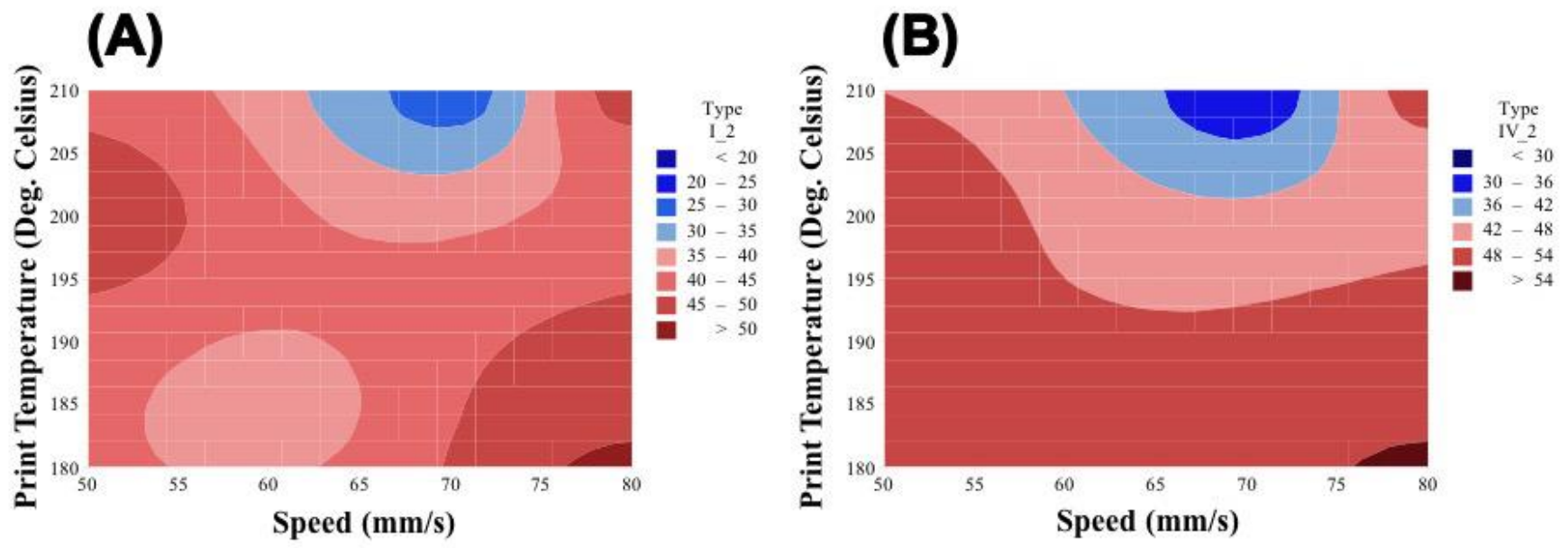

Fig. 10. Contour plot describing maximum UTS (MPa) at a layer height of $0.20 \mathrm{~mm}$. Variable parameters are print speed $(\mathrm{mm} / \mathrm{s})$ and print temperature $\left({ }^{\circ} \mathrm{C}\right)$. (a) Type I, (b) Type IV.

- Type IV Horizontal $\quad \times$ Type IV Verticle

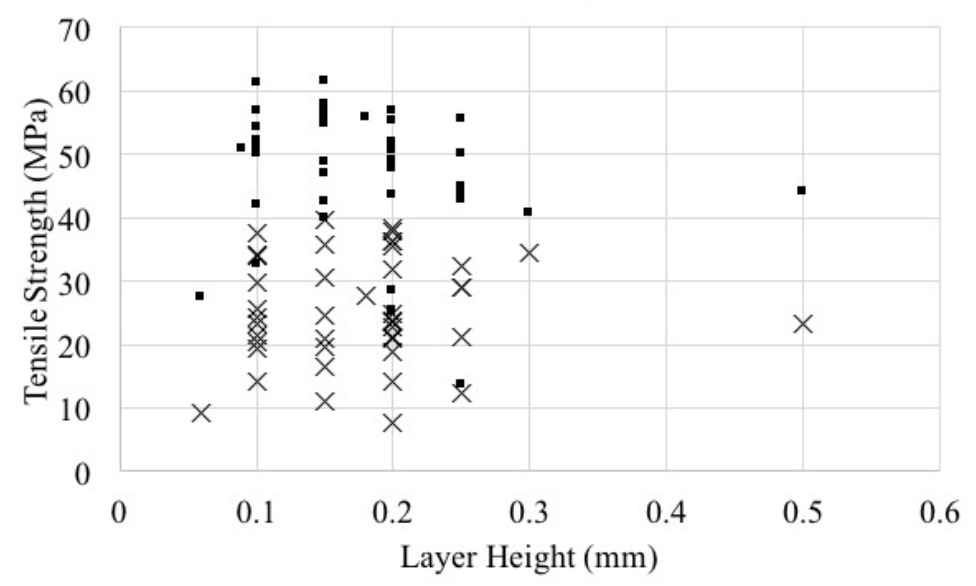

Fig. 11. Ultimate tensile strength (MPa) distribution. ASTM D638-14 Type IV - Horizontal geometries compared against Type IV - Vertical at equivalent printing parameters (e.g. Layer Height (mm)).

- Type IV Horizontal $\times$ Type IV Verticle

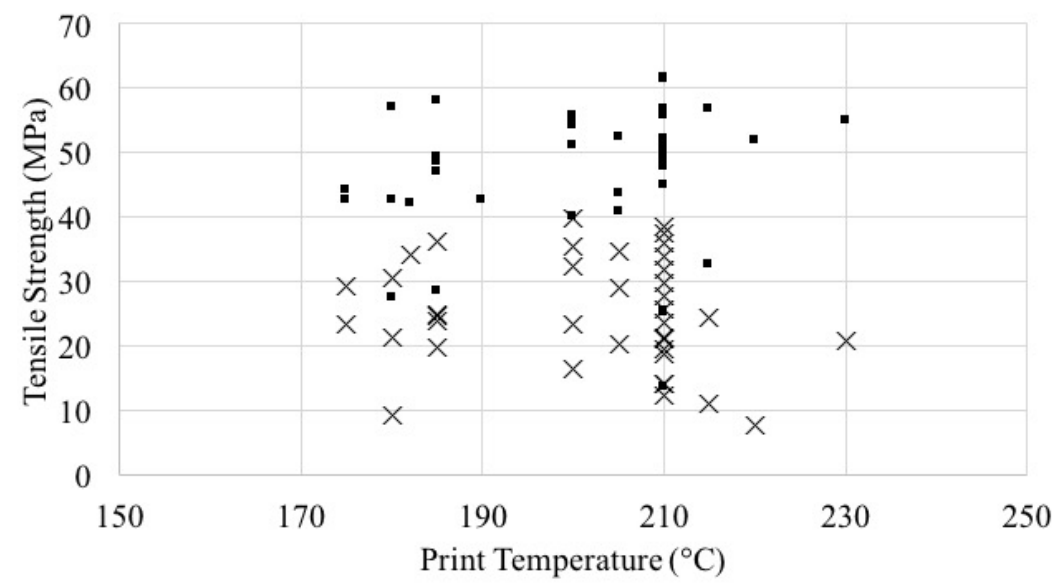

Fig. 12. Ultimate tensile strength (MPa) distribution. ASTM D638-14 Type IV - Horizontal geometries compared against Type IV - Vertical at equivalent printing parameters (e.g. Print Temperature $\left({ }^{\circ} \mathrm{C}\right)$ ). 


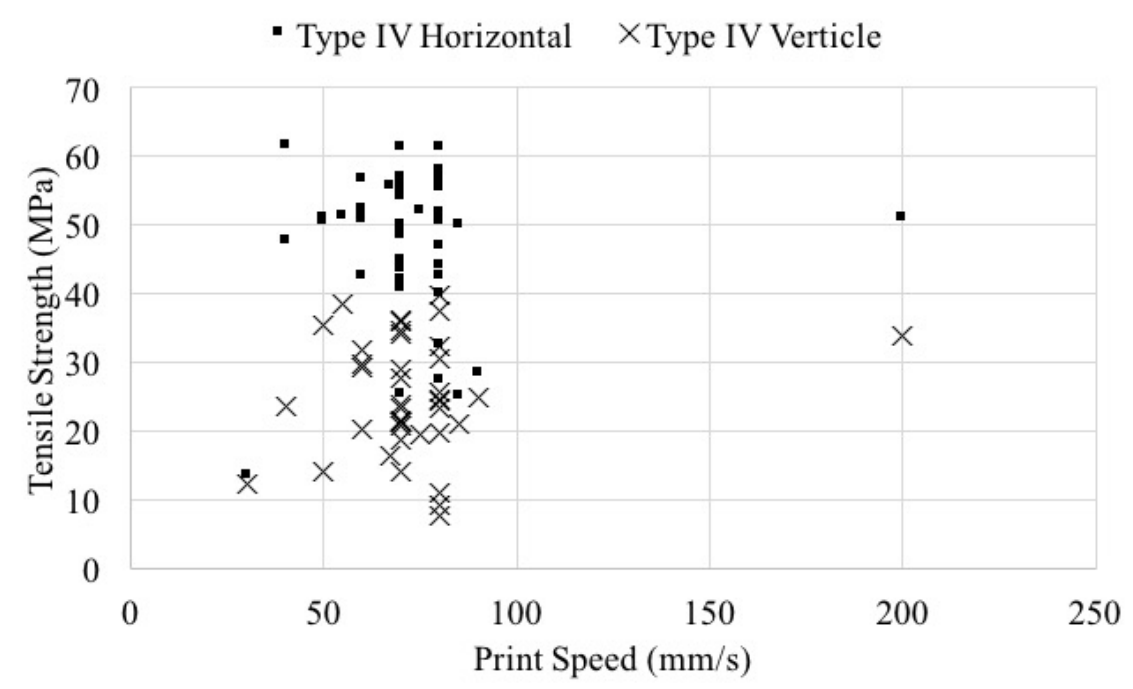

Fig. 13. Ultimate tensile strength (MPa) distribution. ASTM D638-14 Type IV - Horizontal geometries compared against Type IV - Vertical at equivalent printing parameters (e.g. Print Speed (mm/s)).

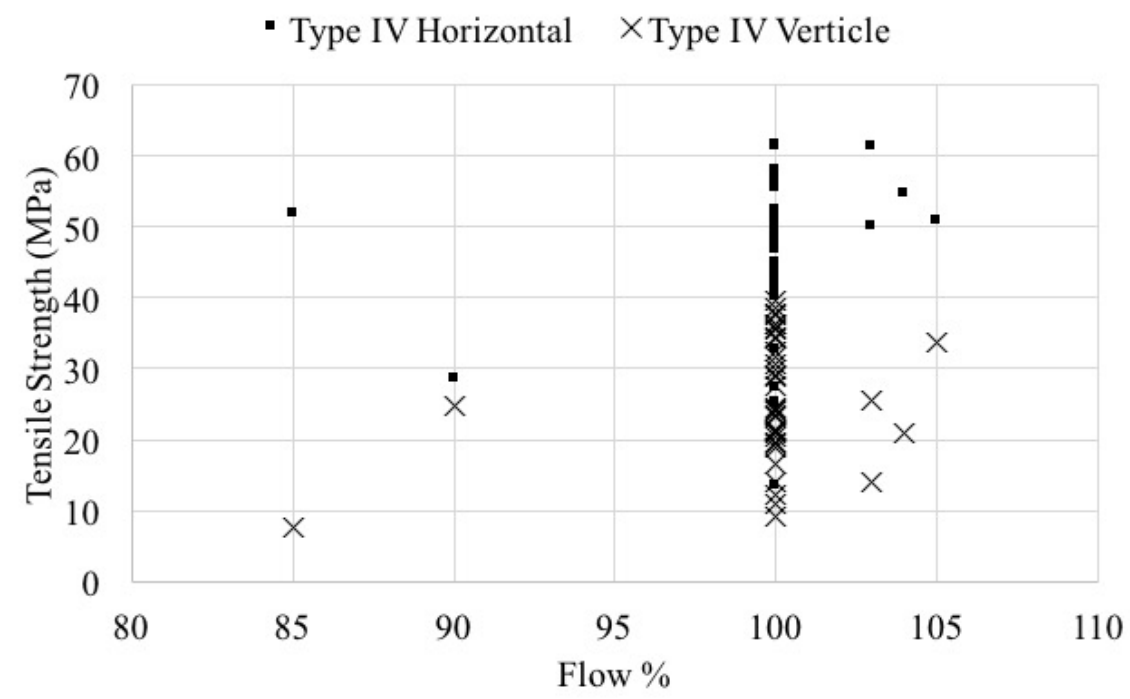

Fig. 14. Ultimate tensile strength (MPa) distribution. ASTM D638-14 Type IV - Horizontal geometries compared against Type IV - Vertical at equivalent printing parameters (e.g. Flow (\%)). 